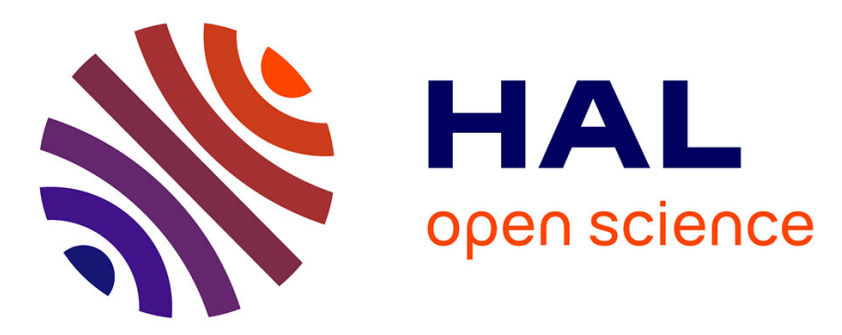

\title{
Real-Time Optimal Control of a 3-phase PMSM in 2-Phase Degraded Mode
}

Olivier Béthoux, Eric Labouré, Ghislain Remy, Éric Berthelot

\section{To cite this version:}

Olivier Béthoux, Eric Labouré, Ghislain Remy, Éric Berthelot. Real-Time Optimal Control of a 3phase PMSM in 2-Phase Degraded Mode. IEEE Transactions on Vehicular Technology, 2016, 99 (PP), pp.1 - 1. 10.1109/TVT.2016.2583662 . hal-01385060

\section{HAL Id: hal-01385060 \\ https://hal.science/hal-01385060}

Submitted on 20 Oct 2016

HAL is a multi-disciplinary open access archive for the deposit and dissemination of scientific research documents, whether they are published or not. The documents may come from teaching and research institutions in France or abroad, or from public or private research centers.
L'archive ouverte pluridisciplinaire HAL, est destinée au dépôt et à la diffusion de documents scientifiques de niveau recherche, publiés ou non, émanant des établissements d'enseignement et de recherche français ou étrangers, des laboratoires publics ou privés. 


\title{
Real-Time Optimal Control of a 3-phase PMSM in 2-Phase Degraded Mode
}

\author{
Olivier Béthoux, Eric Labouré, Ghislain Remy, Eric Berthelot
}

\begin{abstract}
This paper aims to optimize real-time control for the degraded mode of a fault-tolerant power architecture, but not the fault detection and isolation procedure itself. Such power architecture is dedicated to electric vehicles in which it performs the three following essential functions: traction, battery charging and electric grid assistance. For safety reason, in degraded mode, the power control is limited to the traction mode. Thus, for a given torque the proposed innovative strategy uses a novel current/voltage transform which leads to an efficient real-time control of the torque. The key idea is to drive the current without a priori restrictions on its waveform, while minimizing the Joule losses, i.e. the effective value of the current. It has been validated on a laboratory test bench. The studied system is based on a 3phase open-end-winding synchronous machine powered by a 3 full H-bridges inverter. The last section of the paper analyses the comparison between the classic sinusoidal current waveforms and the proposed ones while operating on the two remaining motor phases. It results in a $14 \%$ increase of the torque produced by the permanent magnet machine under test, and a $14 \%$ decrease of the global system losses in traction mode. As a result, the new control strategy enhances traction performance in degraded mode and increases electric vehicle autonomy in postfailure condition.
\end{abstract}

Index Terms - fault-tolerant control, optimization, losses minimization, permanent-magnet synchronous motor (PMSM) drive, phase loss, remedial strategy, real-time.

\section{INTRODUCTION}

E LECTRIC car large-scale deployment requires several key constraints. 1) low purchase and maintenance costs, 2) high energy efficiency in the various modes (traction, recharging, electric grid services), 3) reliability of the vehicle in particular in its traction mode, when safety and availability concerns are crucial. Based on such features, the development of electric vehicles (EVs) could promote sustainable development in both the transportation and electricity production sectors by increasing shares of intermittent

Manuscript received November 23, 2015; revised February 29, 2016; accepted June 13, 2016. This material is based upon work supported by the French automotive cluster MOVEO in a FUI program, through the SOFRACI project.

Copyright (c) 2015 IEEE. Personal use of this material is permitted. However, permission to use this material for any other purposes must be obtained from the IEEE by sending a request to pubs-permissions@iee.org. "

O. Béthoux, E. Labouré and E. Berthelot are with the Group of electrical engineering, Paris (GeePs), University Paris-Sud, Gif-Sur-Yvette 91192, France (e-mail: olivier.bethoux@centralesupelec.fr; eric.laboure@centralesupelec.fr; eric.berthelot@centralesupelec.fr).

G. Remy is with Institut Universitaire Technologique de Cachan (IUTParis11), 94234 Cachan, France (e-mail: ghislain.remy@u-psud.fr). renewable energy sources in a smart electric grid [1], [2]. Several drives [3] and several architectures [4] meet the above criteria. Since 2011, innovative solutions (fig. 1) have been patented for EV power system by the VALEO group [5]-[8]. Precisely the patented power architecture enables to share the three main power functions without using any electric contactor. It is based on a three-phase open-end-winding permanent magnet synchronous machine (PMSM) fed with a power inverter made of three full $\mathrm{H}$-bridges. The DC bus is powered by a high voltage battery using an interleaved buckboost converter.

This solution has proved to be simple, fault-tolerant and energy efficient [9]-[14]. Indeed, this system has already been analyzed and discussed in different ways:

1) Analytical and numerical computing methods to design the synchronous machine (regarding zero-sequence inductance, electromotive force, etc) [9],

2) Innovative techniques for ensuring good performances in electric grid connection mode [10],

3) Improved vector control minimizing current ripple in traction mode [11], new approaches enabling high speed range optimizing air-gap flux-weakening [12], robust methods to track down any possible failures in the drive [13] and simple techniques enabling traction mode without a speed sensor [14].

In real-time control for the degraded mode of a faulttolerant power architecture, Fault Detection and Isolation (FDI), is a major issue [15]. In the studied drive, a fault may occur either in the motor itself or in the voltage PWM inverter [16]-[17].

- The fault has to be detected by the IGBT driver (hardware detection) if an IGBT fails in short-circuit [18]-[19].

- The fault can be detected by a FDI algorithm in the case of an open-phase fault or an open-switch fault. Then, two main approaches can be used: the first FDI technique consists in using normalized dc-components [20]-[21], while the second FDI method involves computing the magnitude and the frequency of the 3phase currents [13].

This current work does not focus on the FDI procedure but intends to enhance drive performances in post-failure functioning, increasing the maximum torque and extending the vehicle's range. Indeed, the above architecture is fault-tolerant since it is able to operate using two out of three phases. For an 


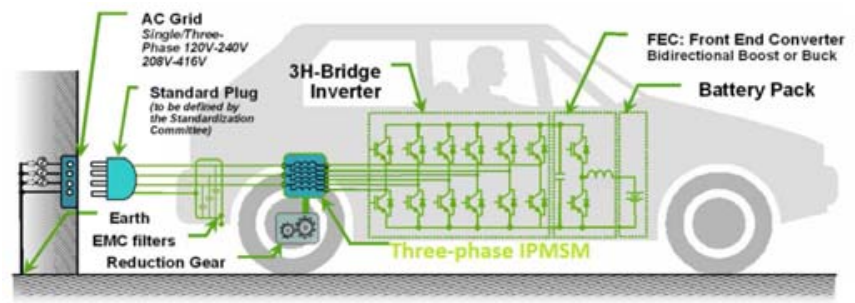

Fig. 1. Innovative power architecture for EV suggested by VALEO [7].

electric vehicle, traction mode is vital and its loss could lead to dramatic consequences. In a fault-tolerant architecture, a phase default is detected (caused by a motor winding or a power switch), the combination of inverter and machine is then reconfigured in order to isolate the faulty phase [22]. S. Bolognani, et al. demonstrated in [23] that using sinusoidal waveforms enables the drive to operate up to $58 \%$ of the rated torque. PMSM are designed and optimized on various criteria (cost, main machine and zero-sequence machine inductances, cooling, ...) leading to a final implementation with most frequently non-sinusoidal electromotive forces (emf). In this situation, the question arises whether the choice of sinusoidal currents in the two remaining phases is relevant for minimizing the drive losses and for maximizing the available torque. This question directly impacts

1) The EV range by improving global efficiency;

2) The availability and the safety of the EV in degraded mode.

Thus, the purpose of the present article is to suggest an optimal strategy to control the PMSM drive in real-time during post-failure operation. The key points are: 1) efficient torque control using a novel current/voltage transform, while keeping a simple and easy-to-tune control algorithm, 2) optimal current references enabling to minimize global drive losses and to maximize drive torque. The paper is organized as follows. Section 2 explains the post-failure drive control structure, describes the developed experimental test bench and shows the drive behavior while using basic sinusoidal current references. Section 3 presents the innovative strategy. Section 4 assesses on an experimental bench its performances against a competing classic approach. Section 5 draws a conclusion and outlines that the proposed control strategy may extend to other drive applications.

\section{THREE-PHASE OPEN-END-WINDING SYNCHRONOUS MACHINE IN TWO-PHASE MODE}

The present section addresses the problem of driving a three-phase synchronous motor using only two of the three phases. To tackle this issue, an innovative reference frame is introduced, allowing the design of a simple control scheme based on PI-controllers; additionally a dedicated space vector (SV) pulse-width modulation (PWM) technique permits to minimize inverter switching losses. This control architecture is successfully implemented on a laboratory test bench. At the end of the section, the latter is presented and a test with classic sinusoidal current references is discussed.

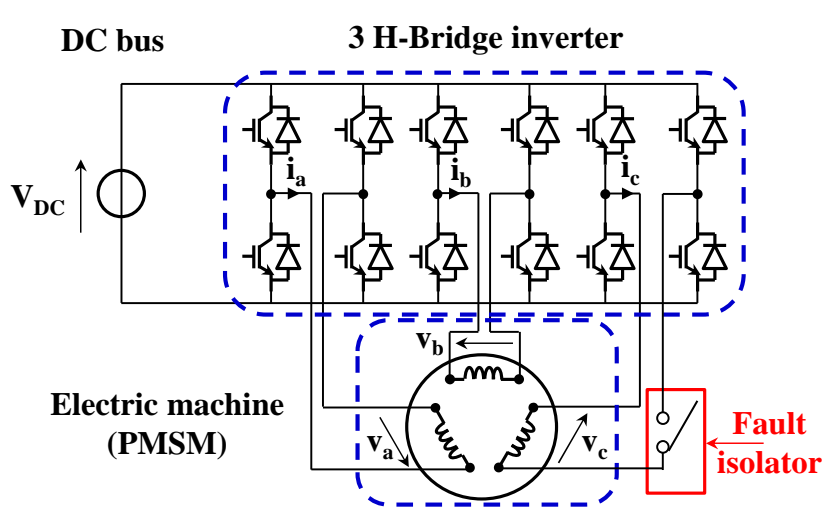

Fig. 2. Synchronous motor drive in degraded mode (third phase disconnected).

\section{A. Electrical model in degraded mode}

The synchronous machine operates according to Faraday law. Within the context of the loss of the third phase (Fig. 2), the two remaining stator currents $\left[\begin{array}{ll}i_{a} & i_{b}\end{array}\right]^{t}$ and stator voltages $\left[\begin{array}{ll}v_{a} & v_{b}\end{array}\right]^{t}$ are described by the following 2-equations system:

$\left[\begin{array}{l}v_{a} \\ v_{b}\end{array}\right]=R\left[\begin{array}{l}i_{a} \\ i_{b}\end{array}\right]+\left[\begin{array}{cc}L & M \\ M & L\end{array}\right] \frac{d}{d t}\left[\begin{array}{l}i_{a} \\ i_{b}\end{array}\right]+\left[\begin{array}{l}e_{a} \\ e_{b}\end{array}\right]$

with $\mathrm{L}$ the phase self-inductance, $\mathrm{M}$ the mutual inductance between two phases, $\mathrm{R}$ the phase resistance and $\left[\begin{array}{ll}e_{a} & e_{b}\end{array}\right]^{t}$ the back electromotive forces (back-emf) induced into the two remaining phases by the rotor movement.

At the shaft rotation speed $\Omega$, currents control enables to generate an instantaneous electromagnetic torque:

$T_{e m}=\left(e_{a} i_{a}+e_{b} i_{b}\right) / \Omega$

To this end, the two machine voltages are produced by the voltage inverter and are computed by a current-controller.

\section{B. Current/voltage transform in degraded mode}

Compared to classical Park and Concordia transform for 3phase machines [24], in degraded mode a novel transform is needed using 2 of the 3 phases. Unlike fault-tolerant PMSM drive, mostly based on electrically and magnetically isolated windings [25]-[26], the studied machine windings are magnetically well coupled to permit an optimized 3-phase or single phase battery charging mode [10]. Therefore, we consider our transform as novel in contrast to the solution adopted in [27] as explained below.

To tackle this two-dimensional control problem, the adopted approach consists of diagonalizing the inductance matrix $L_{a b}$ using an appropriate $T_{22}$ transformation. Matrix $L_{a b}$ eigenvectors are proportional to $\left[\begin{array}{ll}1 & -1\end{array}\right]^{t}$ and $\left[\begin{array}{ll}1 & 1\end{array}\right]^{t}$ and are associated to two distinct eigenvalues, namely $L_{\Gamma}=$ $L-M$ and $L_{\Delta}=L+M$ respectively. Subsequently, the matrix $T_{22}$ is defined by

$T_{22}=\frac{1}{\sqrt{2}}\left[\begin{array}{cc}1 & 1 \\ -1 & 1\end{array}\right]$ 
$T_{22}$ is an orthogonal matrix which 1) enables to diagonalize the real inductance matrix $L_{a b}$ and 2) preserves the power invariance principle since $T_{22}{ }^{t} \cdot T_{22}=I d$. Using the suggested transformation (3) in (1) leads to the following new set of equations which describes the fictitious machine associated to the innovative transform $\mathrm{T}$ :

$\left[\begin{array}{l}v_{\Gamma} \\ v_{\Delta}\end{array}\right]=R\left[\begin{array}{l}i_{\Gamma} \\ i_{\Delta}\end{array}\right]+\left[\begin{array}{cc}L_{\Gamma} & 0 \\ 0 & L_{\Delta}\end{array}\right] \frac{d}{d t}\left[\begin{array}{l}i_{\Gamma} \\ i_{\Delta}\end{array}\right]+\left[\begin{array}{l}e_{\Gamma} \\ e_{\Delta}\end{array}\right]$

where $\left[\begin{array}{ll}i_{\Gamma} & i_{\Delta}\end{array}\right]^{t},\left[\begin{array}{ll}v_{\Gamma} & v_{\Delta}\end{array}\right]^{t}$ and $\left[\begin{array}{ll}e_{\Gamma} & e_{\Delta}\end{array}\right]^{t}$ are the fictitious currents, voltages and back-emf expressed in the new frame.

$\left[\begin{array}{l}i_{a} \\ i_{b}\end{array}\right]=T_{22}\left[\begin{array}{l}i_{\Gamma} \\ i_{\Delta}\end{array}\right] ; \quad\left[\begin{array}{l}v_{a} \\ v_{b}\end{array}\right]=T_{22}\left[\begin{array}{l}v_{\Gamma} \\ v_{\Delta}\end{array}\right] ; \quad\left[\begin{array}{l}e_{a} \\ e_{b}\end{array}\right]=T_{22}\left[\begin{array}{l}e_{\Gamma} \\ \mathrm{e}_{\Delta}\end{array}\right]$

Indeed, the transform proposed in [27] is only validated by simulation, the mutual inductance value $M$ must not be neglected to ensure a pure system decoupling in the fictitious frame; furthermore, the power invariance principle is respected, hence simplifying current references computation from torque demand.

\section{Control scheme in degraded mode}

In a classic way the back-emf $\left[\begin{array}{ll}e_{\Gamma} & e_{\Delta}\end{array}\right]^{t}$ are computed and compensated in the proposed control scheme. Current control can now be achieved using two independent controllers. Each one deals with a linear first order system best suited for classic PI controllers. Fig. 3 depicts the control structure suggested for driving the PM in post-failure mode. It works with fictitious variables based on the measures $\left(\begin{array}{lll}i_{a} & i_{b} & \theta\end{array}\right)$ and the transformation $\left(T_{22}\right)^{-1}=T_{22}{ }^{t}$ and generates the inverter PWM signals directly in the new $\Gamma-\Delta$ frame as explained in the following subsection.

\section{SV-PWM in degraded mode}

A fictitious machine was defined to achieve a simple and efficient control structure of the degraded mode of the 3-phase PMSM working with two out of the three phases. As the PMSM is specifically powered by a voltage inverter, the second crucial issue is to explore its ability to guarantee a space vector control in the degraded mode.

After successful isolation, each of the two healthy $\mathrm{H}$ bridges can still generate three voltage levels, namely $0,+V_{D C}$ and $-V_{D C}$. As a result, the inverter is only able to produce nine discrete space vectors. Using the suggested fictitious machine approach, the output voltage vectors are described in $\Gamma-\Delta$ frame by using the innovative transform in (3). The available discrete voltages are normalized with respect to bus voltage $V_{D C}$ and listed in Table I while Fig.4 illustrates them in $\Gamma-\Delta$ frame.

Both $\mathrm{H}$-bridge inverters can provide an average value of the voltage setpoint $\left[v_{\Gamma}{ }^{*} v_{\Delta}{ }^{*}\right]^{t}$, using SV-PWM technique. For power losses and EMC reasons, it is required to control switching frequency $\left(F_{S W}\right)$. Consequently, the PWM

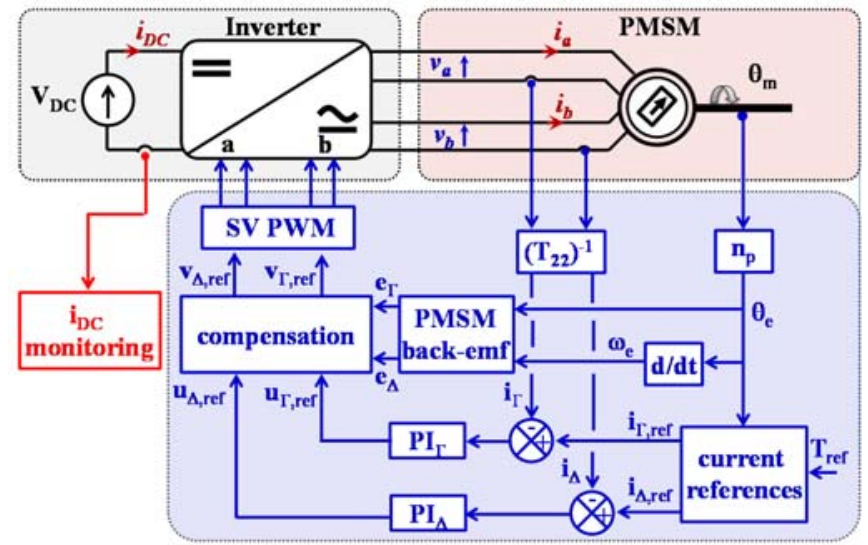

Fig. 3. SM drive control structure in degraded mode.

generation is a 3-dimensional problem: two dimensions are devoted to the fictitious machine and one is dedicated to time. Therefore, 3 different discrete voltage vectors $\left\{\begin{array}{lll}V_{1} & V_{2} & V_{3}\end{array}\right\}$ among the 9 inverter possibilities, are necessary for solving this SV-PWM problem. Noting $T_{S W}=1 / F_{S W}$ the desired switching period, the 3 associated durations $\left\{\begin{array}{llll}\Delta t_{1} & \Delta t_{2} & \Delta t_{3}\end{array}\right\}$ are computed using the following equation:

$\left[\begin{array}{c}v_{\Gamma}{ }^{*} \\ v_{\Delta}{ }^{*} \\ 1 / 2\end{array}\right]=\frac{1}{T_{S W}}\left[\begin{array}{ccc}V_{\Gamma 1} & V_{\Gamma 2} & V_{\Gamma 3} \\ V_{\Delta 1} & V_{\Delta 2} & V_{\Delta 3} \\ 1 & 1 & 1\end{array}\right]\left[\begin{array}{l}\Delta t_{1} \\ \Delta t_{2} \\ \Delta t_{3}\end{array}\right]$

The set of three voltage vectors is chosen to guarantee that any $\Delta t_{k}$ is positive. The main issue is to select the most relevant one [22], [28]. As depicted in Fig. 4, eight sectors are delimited by eight non-zero voltages. From this representation, it clearly appears that reducing voltage differences leads to decreased voltage ripples, which implies using adjacent vectors of the sector under consideration. Reducing switching losses is important [29] to improve the inverter reliability because thermal stress (due to losses) is a key factor in the acceleration of the failure mechanism process [30]. Indeed, the switching losses are mostly an important part of the semiconductor power losses [31]. Hence, switching frequency should decrease; leading to generate higher current ripple magnitude and so additional losses [32]. To reduce it, as switching frequency cannot be increased, the trade-off has to be done by the switching control strategy. Then, it is crucial to build a sequence guaranteeing an equitable switching distribution between legs. It is also important to obtain a limited number of switching and to avoid over-switching while changing from one sector to another.

In conclusion, the reference vector is located in a unique sector associated to a single set of three voltages (zero voltage and two active vectors). For example in Fig. 4, sector $I$ is delimited by the three discrete voltages $V_{9}, V_{3}$ and $V_{1}$. The proposed switching sequence associated to this sector is illustrated in Fig. 5. Each single H-bridge needs only one switching, 1 turn-on or 1 turn-off during $T_{s w} / 2$. Finally, the minimization of the switching losses and their equitable distribution requirements are therefore fulfilled. 
TABLE I

REMAINING STATOR VOLTAGES IN A-B AND $\Delta$ - $\Gamma$ FRAMES

\begin{tabular}{ccccc}
\hline \hline VECTORS & $\mathrm{V}_{\mathrm{a}}$ & $\mathrm{V}_{\mathrm{b}}$ & $\mathrm{V}_{\Gamma}$ & $\mathrm{V}_{\mathrm{D}}$ \\
\hline $\mathrm{V}_{1}$ & 0 & 0 & 0 & 0 \\
\hline $\mathrm{V}_{2}$ & 0 & -1 & $-1 / \sqrt{2}$ & $-1 / \sqrt{2}$ \\
\hline $\mathrm{V}_{3}$ & 0 & +1 & $1 / \sqrt{2}$ & $1 / \sqrt{2}$ \\
\hline $\mathrm{V}_{4}$ & -1 & 0 & $-1 / \sqrt{2}$ & $1 / \sqrt{2}$ \\
\hline $\mathrm{V}_{5}$ & -1 & -1 & $-\sqrt{2}$ & 0 \\
\hline $\mathrm{V}_{6}$ & -1 & +1 & 0 & $\sqrt{2}$ \\
\hline $\mathrm{V}_{7}$ & +1 & 0 & $1 / \sqrt{2}$ & $-1 / \sqrt{2}$ \\
\hline $\mathrm{V}_{8}$ & +1 & -1 & 0 & $-\sqrt{2}$ \\
\hline $\mathrm{V}_{9}$ & +1 & +1 & $\sqrt{2}$ & 0 \\
\hline \hline
\end{tabular}

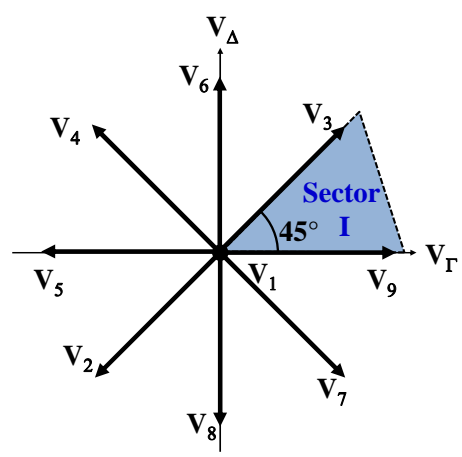

Fig. 4. $2 \mathrm{H}$-Bridges inverter switching states and space vectors in $\Gamma-\Delta$ frame.

\begin{tabular}{|c|c|c|c|c|c|}
\hline \multicolumn{3}{|c|}{$\mathbf{T}_{\mathrm{SW}} / 2$} & \multicolumn{3}{|c|}{$\mathbf{T}_{\mathrm{SW}} / 2$} \\
\hline$\Delta \mathrm{t}_{1}$ & $\Delta \mathbf{t}_{3}$ & $\Delta \mathrm{t}_{9}$ & $\Delta \mathrm{t}_{9}$ & $\Delta \mathbf{t}_{3}$ & $\Delta t_{1}$ \\
\hline $\mathrm{V}_{1}$ & $\mathbf{V}_{3}$ & $V_{9}$ & $V_{9}$ & $\mathbf{V}_{3}$ & $\mathrm{~V}_{1}$ \\
\hline
\end{tabular}

Fig 5. Switching temporal distribution in the 2 H-bridges inverter.

\section{E. Torque control implementation using classic references}

The suggested remedial control structure has been implemented and validated on an experimental test bench specifically designed for the study of the EV power architecture patented by VALEO (Fig. 1). Following a brief presentation of the experimental setup (Fig. 6), validation tests based on classic sinusoidal references are discussed underlying the performance limits. To overcome the limitations due to this basic strategy and enhance remedial strategy performance, the next section proposes a comprehensive optimization.

\section{1) SM under test and experimental setup}

The PM motor drive under test consists of an 8-pole 3phase open-end-winding PMSM (LEROY SOMER) supplied by an inverter composed of 3 full $\mathrm{H}$-bridges powered by the same DC bus. The latter is fed by a $3.3 \mathrm{~kW}$ DC supply source (AGILENT) adjusted to its $300 \mathrm{~V}$ rated voltage. The PMSM is coupled to an induction machine (IM) mechanically. Using a dedicated industrial drive (OMRON), the IM operates in speed control. It allows mimicking the PMSM mechanical load and can work in either regenerative braking or traction modes. The key PMSM features are summarized in Table II. Each of its phases is equipped with a Hall effect current sensor (LEM).

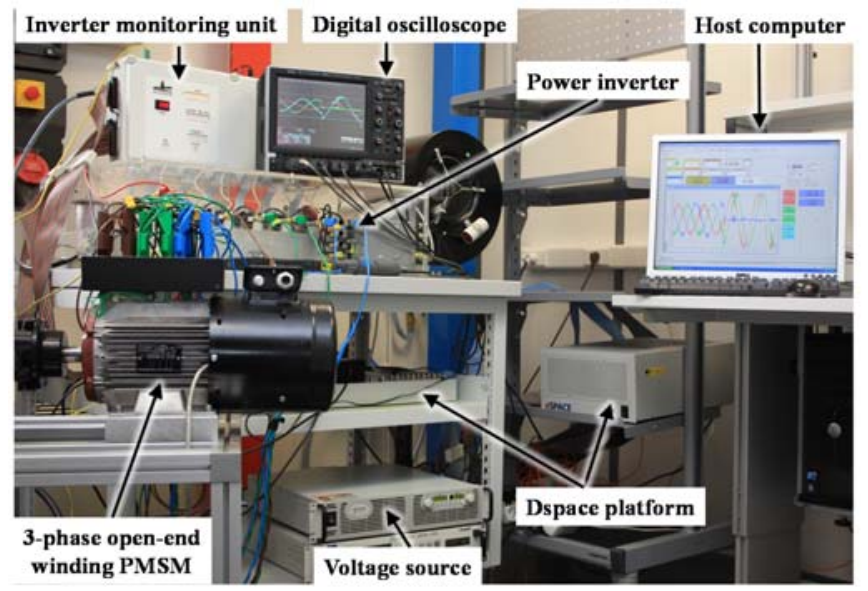

Fig. 6. Experimental setup view.

TABLE II

LEROY SOMER LS 132 S SYNCHRONOUS MOTOR PARAMETERS

\begin{tabular}{lll}
\hline Symbol & \multicolumn{1}{c}{ Parameter } & \multicolumn{1}{c}{ Value } \\
\hline $\mathrm{R}$ & Stator phase resistance & $1.72 \Omega$ \\
$L_{d}$ & d-axis self-inductance & $14 \mathrm{mH}$ \\
$L_{q}$ & q-axis self-inductance & $12.5 \mathrm{mH}$ \\
$p$ & number of motor pole pairs & 4 \\
$\Psi_{M}$ & amplitude of the induced flux & $0.494 \mathrm{~Wb}$ \\
$\mathrm{~K}_{\mathrm{SM}, 1}$ & $1^{\text {st }}$ harmonic back-e.m.f. constant & $1.417 \mathrm{~V} \mathrm{~s}$ \\
$\mathrm{~K}_{\mathrm{SM}, 3}$ & $3^{\text {rd }}$ harmonic back-e.m.f. constant & $0.0354 \mathrm{~V} \mathrm{~s}$ \\
$\mathrm{~K}_{\mathrm{SM}, 5}$ & $5^{\text {th }}$ harmonic back-e.m.f. constant & $0.0354 \mathrm{~V} \mathrm{~s}$ \\
$\mathrm{I}_{\text {rated }}$ & Rated current & $10 \mathrm{~A}$ \\
\hline \hline
\end{tabular}

An incremental encoder (IVO Industry) coupled with the PMSM shaft enables the precise determination of the rotor position (its resolution is of 2500 points per revolution).

The control of the PMSM - inverter combination is implemented in a DSPACE real-time system. It is composed of a DS 1106 main card and secondary DS 3001 and DS 5203 cards. DS 3001 enables to determine the absolute rotor position. DS 5203 is based on a FPGA Xilinx Virtex ${ }^{\circledR} 5$ driven with a $100 \mathrm{MHz}$ clock. The suggested $20 \mathrm{kHz}$ SVPWM is implemented in it. It also performs analog-to-digital conversions at the switching frequency rate. This frequency is used to synchronize the DS1106 microprocessor in which current control is implemented.

\section{2) Control structure validation using classic strategy}

To validate the proper functioning of the global system with the suggested control part, the first test consists in using the classic sinusoidal waveform strategy. Within this context, outputs calculated by the "current references" function block are based on the torque reference T and the electric angle $\theta_{e}$.

$\left[\begin{array}{l}i_{a, \text { ref }} \\ i_{b, \text { ref }}\end{array}\right]=\left(\frac{T}{K_{S M, 1} \cdot \sqrt{3}}\right) \cdot \sqrt{2} \cdot\left[\begin{array}{c}\sin \left(\theta_{e}-\pi / 6\right) \\ \sin \left(\theta_{e}-2 \pi / 3+\pi / 6\right)\end{array}\right]$

The required fictitious current references $\left[\begin{array}{ll}i_{\Delta, \text { ref }} & i_{\Gamma, \text { ref }}\end{array}\right]^{t}$ can therefore be inferred from the suggested transform $\left(T_{22}\right)^{-1}$ as described in (5). 
As the ultimate objective is to ensure continuity of service in traction mode, the remedial strategy is applied immediately after a phase default occurs. This default is simulated on phase "c" and it is assumed that the fault is detected and isolated instantaneously and the phase "c" is immediately disconnected by its phase isolator. For this test, the PMSM delivers 20 N.m of torque and is loaded by the IM which maintains a $600 \mathrm{r} \cdot \mathrm{min}^{-1}$ constant rotational speed. The oscilloscope is triggered at a time when the phase fault is simulated (Fig. 7). On the left-hand side of the picture are captured phase and DC bus currents in normal condition, while the post-failure behavior is shown on the right. The remedial control structure fully allows to track the calculated current references: remaining currents become $\sqrt{3}$ times larger than in normal mode and are with $60^{\circ}$ phase shift. However, it is important to note that a significant current ripple appears on the DC current $i_{D C}$ feeding the inverter. The oscillation frequency is twice the electric frequency. This natural phenomenon occurs because of back-emf harmonics which have not been yet considered. It is fully consistent with the simulation analyses presented in [17] where authors mention an additional torque ripple due to harmonics in emf and saliency effect.

This proves that the classic strategy does not sufficiently address the problem of driving the proper remedial currents. Therefore, section III tackles their optimization and section IV compares, on the developed test bench, the suggested solution with the classic sinusoidal strategy.

\section{Current Optimization in Degraded Mode}

Most classical control strategies of PMSM aim to achieve the required torque while minimizing the Joule losses [33]. Indeed, Joule losses induce motor and inverter thermal stresses which affect their reliability [34] and also reduce the global car driving range due to a decline in power efficiency. However these classic approaches usually consider pure sinusoidal back-emf in the PMSM. They also force pure sinusoidal currents in both the normal and degraded modes of operation [27], and may improve the drive performance by adding a third-harmonic component [35], [36]. Generally speaking, the addressed optimization problem consists in defining the best trajectory between two given points, namely the current waveform for one motor revolution, while respecting a constraint, namely a constant torque. The EulerLagrange method has historically been developed for this class of problem [37], [38] and successfully used for current optimization in PMSM [33], [39]. Consequently, the EulerLagrange procedure is used in this particular case and applied in its generality. The obtained analytical form will be discussed subsequently.

In the event of any back-emf, this section aims to minimize the Joule losses while achieving a constant electromagnetic torque $\mathrm{T}$ in steady state operation. The criterion used is therefore described by the functional $J\left(i_{a}, i_{b}\right)$ defined by:

$J\left(i_{a}, i_{b}\right)=\int_{0}^{T_{e}}\left[i_{a}(t)^{2}+i_{b}(t)^{2}\right] d t$

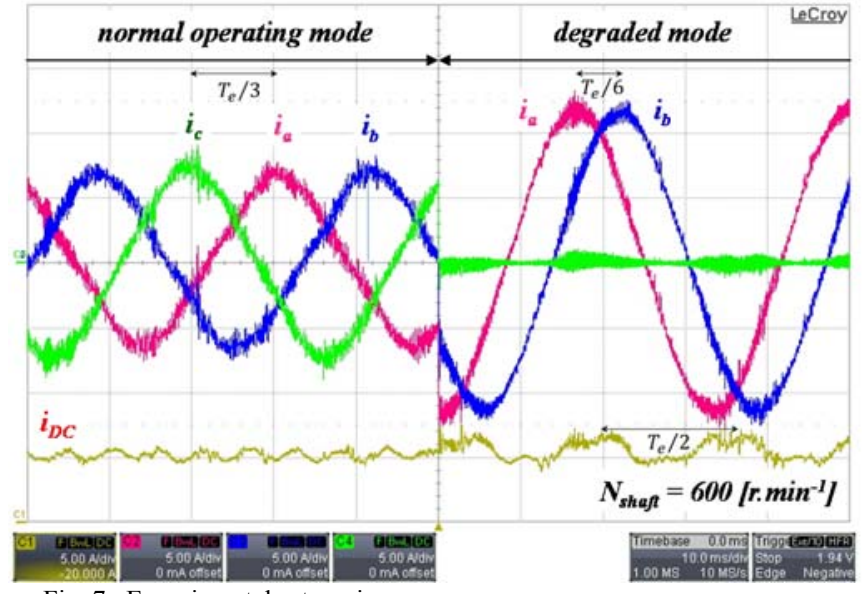

Fig. 7. Experimental setup view.

Subject to the one simple constraint of constant power defined by $P_{e m}=T \Omega$ :

$f\left(i_{a}, i_{b}, t\right)=\left[\left(e_{a}(t) i_{a}(t)\right)+\left(e_{b}(t) i_{b}(t)\right)\right]-P_{e m}=0$

To address this single constraint mathematical optimization, a new single Lagrange-multiplier variable $\lambda(t)$ is introduced and the minimum of the unconstrained augmented functional $J_{a}\left(i_{a}, i_{b}, \lambda\right)$ is sought :

$J_{a}\left(i_{a}, i_{b}, \lambda\right)=\int_{0}^{T_{e}}\left[i_{a}(t)^{2}+i_{a}(t)^{2}+\lambda(t) f\left(i_{a}, i_{b}, t\right)\right] d t$

A necessary condition for $J_{a}\left(i_{a}, i_{b}, \lambda\right)$ optimality is that the partial derivatives of the Lagrange function are zero at any time [37], which means that:

$$
\left\{\begin{array}{c}
2 i_{a}(t)+e_{a}(t) \lambda(t)=0 \\
2 i_{b}(t)+e_{b}(t) \lambda(t)=0 \\
e_{a}(t) i_{a}(t)+e_{b}(t) i_{b}(t)-P_{e m}=0
\end{array}\right.
$$

Solving this set of three equations with the three unknowns $\left(i_{a}, i_{b}, \lambda\right)$ yields the following solution:

$$
\left\{\begin{aligned}
i_{a}(t)= & P_{e m} \cdot e_{a}(t) /\left[e_{a}(t)^{2}+e_{b}(t)^{2}\right] \\
i_{b}(t)= & P_{e m} \cdot e_{b}(t) /\left[e_{a}(t)^{2}+e_{b}(t)^{2}\right] \\
& \lambda(t)=2 i_{a}(t) / e_{a}(t)
\end{aligned}\right.
$$

Consequently, it leads to a substantially different strategy than the classic solution which arises from the sinusoidal waveform constraint.

Specifically, even though considering pure sinusoidal backemf shape, (13) provides current waveforms completely different from the ones given by (7) and exhibited in [17] for instance.

$\left[\begin{array}{l}i_{a} \\ i_{b}\end{array}\right]=\frac{T \sqrt{2}}{K_{S M, 1}}\left[\begin{array}{c}\sin \left(\theta_{e}\right) /\left[2-\cos \left(2 \theta_{e}+\pi / 3\right)\right] \\ \sin \left(\theta_{e}-2 \pi / 3\right) /\left[2-\cos \left(2 \theta_{e}+\pi / 3\right)\right]\end{array}\right]$

Indeed the current references in the two healthy phases no longer have sinusoidal shapes and are phase shifted by $T_{e} / 3$ 
instead of $T_{e} / 6$. The power output by phase is therefore quite different. Optimizing without preconceived waveforms increases the current level when the absolute value of the phase back-emf is large. Similarly, current and related backemf cross the zero point simultaneously. It induces that around this point the phase power is negligible which implies a maximum power in the other remaining phase. It is for that reason that current and back-emf are in phase and that the phase current peak occurs close to the time when the other back-emf is zero. The current peak value is slightly higher with the calculated waveforms than with pure sinusoidal shapes. Moreover, it is important to notice in this latter case that there is an additional torque ripple with a magnitude of about 13 percent of the mean torque.

Now, considering the real back-emf measured on the PMSM under test, we are able to calculate the current reference waveforms minimizing the unconstrained augmented functional (10). Fig. 8 depicts current references in both cases, namely classic sinusoidal waveforms and calculated waveforms for an operating condition defined by $T=20 \mathrm{Nm}$ and $N=600 \mathrm{r} \mathrm{min}^{-1}$. We can verify in Fig. 8 that the calculated currents effectively lead to a constant electromagnetic torque. These very encouraging results must be confirmed on the developed test bench in order to assess the increase of the maximal torque and also the power efficiency enhancement. To achieve this result, the current control implementation relies on the control scheme described in the previous section (Fig. 3) and using the novel transform. Thus the proposed current reference is controlled in the suggested $\Gamma \Delta$-frame. The main electrical variables are depicted in the $\Gamma \Delta$-frame in Fig. 9: the back-emf is required for forward compensation, each phase current is zero at the same time as the corresponding emf and the voltage is the control value driving the SVPWM block. In our control scheme, two PI controllers are used. The time constant and gain of these two PI are calculated in order to guaranty the closed-loop stability and ensure a sufficient gain at the fundamental frequency of the reference currents in order to reduce errors at this frequency.

\section{INNOVATIVE APPROACH PROOF OF CONCEPT}

The present section assesses and benchmarks the performance of both the classic strategy and the suggested one using the test bench described in section II.

In order to compare the two approaches, Tab. III gives RMS and peak-to-peak current values in steady state, namely at $20 \mathrm{Nm}$ and $600 \mathrm{r} \cdot \mathrm{min}^{-1}$. Obviously, constraining the current waveform to be sinusoidal yields a greater RMS current: the RMS value of suggested currents is 6 percent lower than in the classic scenario. By contrast, relaxing the current shape constraint provides a higher peak value, namely 13 percent higher than in the classic scenario. Indeed, as both current and back-emf are zero simultaneously, the second remaining current has to be greater around this point so as to compensate the phase power decrease. Fig. 10 presents the two

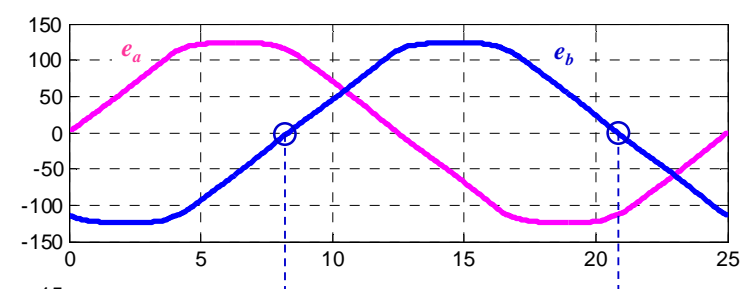

a)

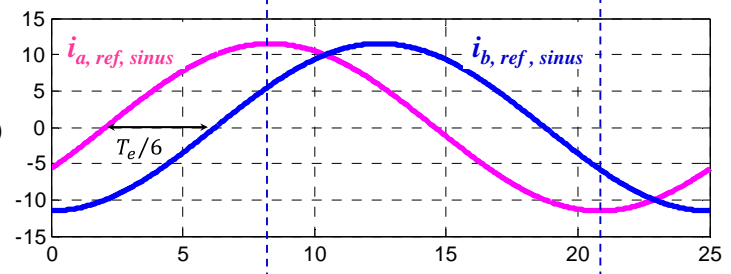

b)

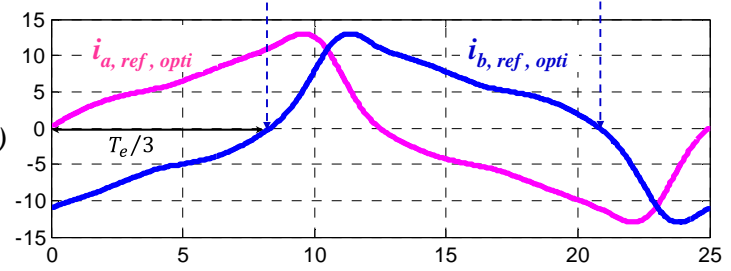

a)

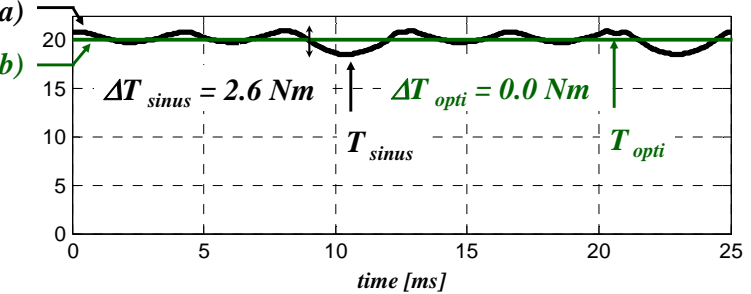

Fig. 8. Optimal current references at $N=600 \mathrm{r} \mathrm{min}^{-1}$ and $T=20 \mathrm{Nm}$

a) Considering pure sinusoidal waveform constraint;

b) Considering no waveform constraint.
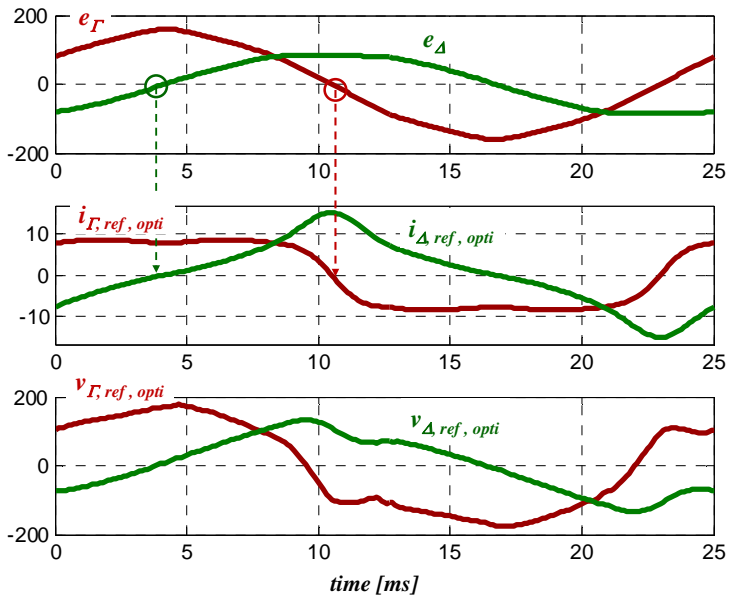

Fig. 9. PMSM drive fictitious variables in the $\Gamma \Delta$-frame with optimal currents in degraded mode at $N=600 \mathrm{r} \mathrm{min}^{-1}$ and $=20 \mathrm{Nm}$.

experimental currents using a trigger moment based on backemf crossing zero; one can see that phase $b$ current reaches its maximal value around this point in time.

Nevertheless, the entire power balance of the drive in remedial strategy shown in Fig. 11 clearly highlights that losses are significantly reduced for a given torque; 14 percentage points represent a significant difference between 
TABLE III

RMS AND PEAK-TO-PEAK CURRENT VALUES @ $\left(20 \mathrm{Nm}, 600 \mathrm{r} \cdot \mathrm{min}^{-1}\right)$

\begin{tabular}{ccc}
\hline \hline Strategy & RMS current & $\begin{array}{c}\text { peak-to-peak } \\
\text { current }\end{array}$ \\
\hline constraint of sinusoidal waveform & $7.70 \mathrm{~A}$ & $11.53 \mathrm{~A}$ \\
No waveform constraint & $8.15 \mathrm{~A}$ & $13.01 \mathrm{~A}$ \\
\hline \hline
\end{tabular}

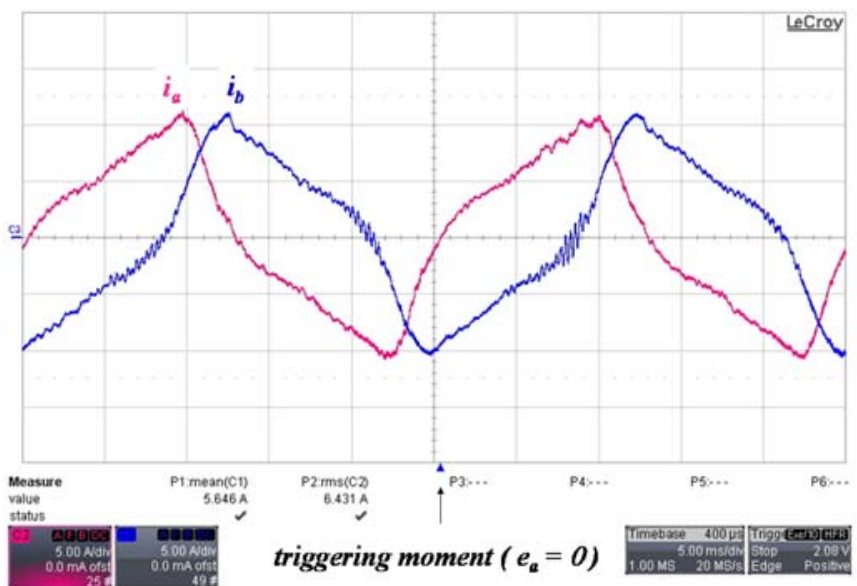

Fig. 10. Steady state currents in post-failure operation mode using the suggested strategy: $N=600 \mathrm{r} \cdot \mathrm{min}^{-1}$ and $T=17 \mathrm{~N} . \mathrm{m}$.

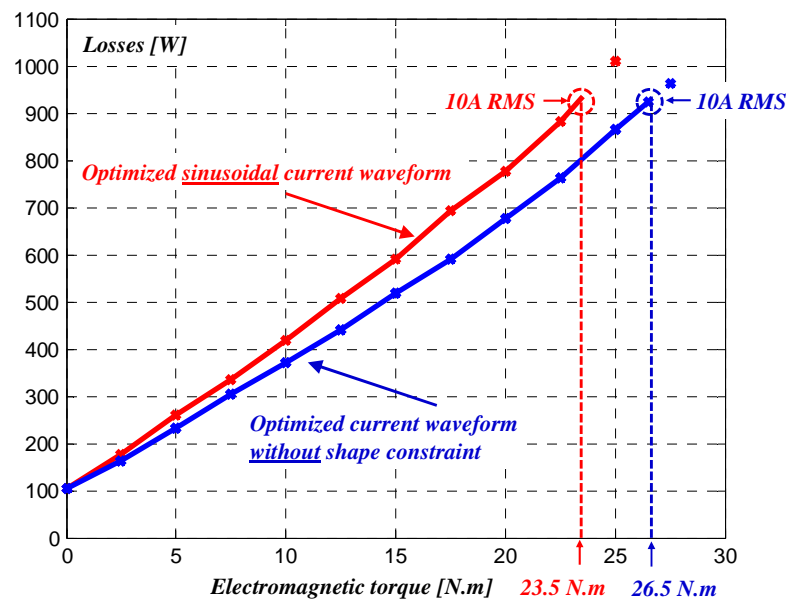

Fig. 11. Losses comparison of both remedial strategies $\left(N=600 \mathrm{r} \cdot \mathrm{min}^{-1}\right)$

the two situations under test. In concrete terms, this enables to enhance accordingly the vehicle range in post-failure operation. Similarly, the torque is increase by $14 \%$ while operating at the same RMS current value. In practical terms, since the effective current is limited for thermal concern, this allows to perform a higher torque in remedial strategy, hence enhancing the traction mode function availability.

Last but not least, Fig. 12 shows that the overall suggested strategy is relevant to achieve transient objectives of a drive. For this validation, the torque reference consists in a square waveform characterized by a $15 \mathrm{Nm}$ low level and a $25 \mathrm{Nm}$ high level. Fig. 12 shows that the current transient is effective with a response time of about $4 \mathrm{~ms}$. This ensures the immediate response to driver demand, i.e. acceleration or braking.

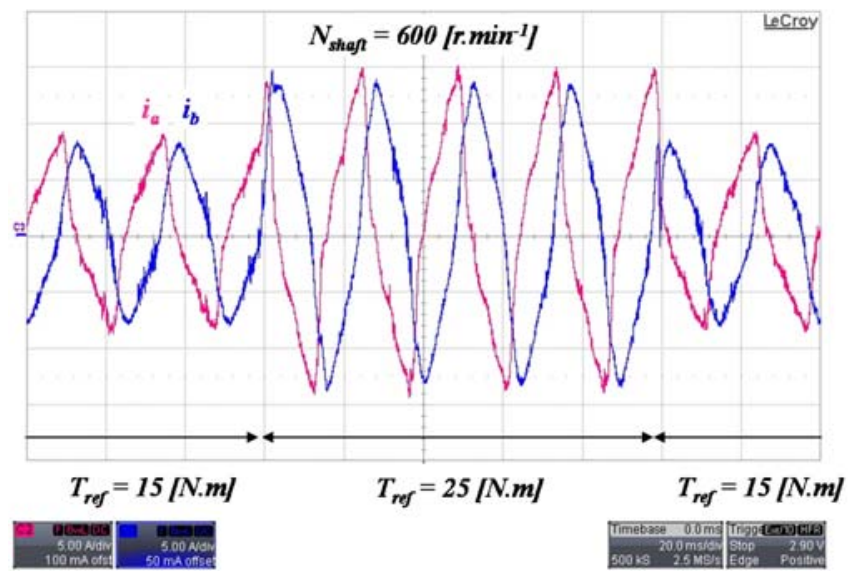

Fig. 12. Torque transient in post-failure operation mode: $N=600 \mathrm{r} \cdot \mathrm{min}^{-1}$ and $T=15 \mathrm{Nm} \leftrightarrow 25 \mathrm{Nm}$.

\section{CONCLUSion AND PeRspectives}

This paper aims to optimize the post-failure traction mode of a fault-tolerant power architecture dedicated to electric vehicles. The studied electric powertrain is based on a 3-phase PMSM. Considering degraded mode operation on two of the three phases, the study tackles the problem of optimal constant torque generation, and additionally, the drive losses are minimized. The related current waveforms are expressed analytically, which leads to a generic solution easy to transpose to any synchronous machine.

In order to validate the innovative strategy, an experimental test bench has been developed and a control scheme has been designed, implemented and validated. As soon as a default is detected in one phase, the control system switches from $d-q$ reference frame to the suggested post-failure reference frame; it enables a proper functioning in degraded mode. In particular, the post-failure control structure permits

1) A simple PI controller tuning through truly decoupled system and back-emf compensation.

2) Optimized functioning of the inverter through a dedicated SVPWM.

3) A good switching from normal mode to remedial mode.

Moreover, a comparative study has been carried out between a classic strategy based on sinusoidal current waveform and the proposed strategy with no preconceived waveform consideration. Regarding the combination of the inverter and the PMSM under test, the major conclusions that can be drawn from this paper are listed as follows.

1) Motor drive losses are reduced by $14 \%$, thereby enhancing the electric vehicle range in degraded mode, which provides the driver with a higher chance to reach a maintenance point.

2) Moreover, the reduction of thermal stress benefits the reliability in post-failure mode, which is a second keypoint.

3) Maximal motor drive torque is increased by $14 \%$, thereby improving the capacity to control the electric vehicle when a failure occurs, which benefits security 
issues.

It has been shown experimentally that optimizing the current control strategy enhances PMSM drive performances in post-failure mode significantly. Additionally, the proposed strategy fits most PMSM drives since the current references are given analytically Possible future work in the area is to generalize this approach to the other types of electric motors used in electric vehicles, namely induction machines and variable reluctance machines.

\section{ACKNOWLEDGEMENTS}

This work was supported by the French automotive cluster MOVEO in a FUI program, through the SOFRACI project.

\section{REFERENCES}

[1] E.S.Rigas, S.D. Ramchurn, N. Bassiliades, "Managing Electric Vehicles in the Smart Grid Using Artificial Intelligence: A Survey", IEEE Trans. on Intell. Transp. Syst., Vol. 16, no. 4, pp: 1619 - 1635, Aug. 2015.

[2] J. de Santiago, H. Bernhoff, B. Ekergård, S. Eriksson, S. Ferhatovic, R. Waters, RM. Leijon, "Electrical Motor Drivelines in Commercial AllElectric Vehicles: A Review", IEEE Trans. Veh. Technol., Vol. 61, no. 2, pp 475 - 484, Feb. 2012

[3] G. Shuang Gao, K.T. Chau, L. Chunhua, W. Diyun, C.C. Chan, "Integrated Energy Management of Plug-in Electric Vehicles in Power Grid With Renewables", IEEE Trans. Veh. Technol., Vol. 63, no. 7, pp. 3019 - 3027, Sept. 2014

[4] N. Sakr, D. Sadarnac, A. Gascher, "A review of on-board integrated chargers for electric vehicles”, in Proc. EPE'14-ECCE Europe, 2014 Lappeenranta, pp 1 - 10

[5] L. De Sousa and B. Bouchez, "Combined Electric Device for Powering and Charging", US Patent 20110221363 A1, Sept. 15, 2011

[6] L. De Sousa and B. Bouchez, "Method and Electric Combined Device for Powering and Charging with Compensation Means", US Patent 20120019173 A1, Jan. 26, 2012.

[7] L. De Sousa, B. Bouchez, and J. L. Da Costa, "Method of exchanging electrical energy between an electrical network conveying a dc or ac electrical quantity and an electrical energy storage unit for hybrid or electric vehicle", European Patent EP2794343 A2, Oct. 29, 2014.

[8] B. Bouchez and L. De Sousa, "Charge transfer device and associated management method”, US Patent US20140042807 A1, Feb. 13, 2014.

[9] H. Dogan, L. Garbuio, H. Nguyen-Xuan, B. Delinchant, A. Foggia F.Wurtz, "Multistatic Reluctance Network Modeling for the Design of Permanent Magnet Synchronous Machines”, IEEE Trans. Magn., Vol. 49 , no. 5, pp 2347 - 2350, May 2013

[10] S. Lacroix, E. Labouré, and M. Hilairet, "An integrated fast battery charger for electric vehicle”, in Proc. VPPC 2010, 2010, Lille, pp. 1-6.

[11] A. Bruyère, L. De Sousa, B. Bouchez, P. Sandulescu, X. Kestelyn, E. Semail, "A multiphase traction/fast-battery-charger drive for electric or plug-in hybrid vehicles: Solutions for control in traction mode", in Proc. VPPC 2010, 2000, Lille, pp. 1-7.

[12] P. Sandulescu, F. Meinguet, X. Kestelyn, E. Semail, A. Bruyere, "Control Strategies for Open-End Winding Drives Operating in the Flux-Weakening Region," IEEE Trans. on Power Electron., Vol. 29, no. 9, pp 4829 - 4842, Sept. 2014.

[13] F. Meinguet, P. Sandulescu, X. Kestelyn, E. Semail, "A Method for Fault Detection and Isolation Based on the Processing of Multiple Diagnostic Indices: Application to Inverter Faults in AC Drives", IEEE Trans. Veh. Technol., Vol. 62, no. 3, pp 995 - 1009, March 2013.

[14] S. Diao, D. Diallo, Z. Makni, C. Marchand, J. -F. Bisson, “A Differential Algebraic Estimator for Sensorless Permanent-Magnet Synchronous Machine Drive", IEEE Transactions on Energy Conversion, Volume: 30, Issue: 1, pp 82 - 89, March 2015.

[15] M.E.H. Benbouzid, D. Diallo, M. Zeraoulia, "Advanced Fault-Tolerant Control of Induction-Motor Drives for EV/HEV Traction Applications: From Conventional to Modern and Intelligent Control Techniques", IEEE Trans. Veh. Technol., Vol. 56, no. 2, March 2007, pp. 519 - 528,

[16] F. Zidani, D. Diallo, M.E.H. Benbouzid, R. Nait-Said, “A Fuzzy-Based Approach for the Diagnosis of Fault Modes in a Voltage-Fed PWM
Inverter Induction Motor Drive”, IEEE Trans. Ind. Electron., Feb. 2008, Vol. 55, no. 2, pp. $586-593$.

[17] S. Yang, A. Bryant, P. Mawby, D. Xiang, L. Ran, and P. Tavner, "An industry-based survey of reliability in power electronic converters," IEEE Trans. Ind. Appl., vol. 47, no. 3, pp. 1441-1451, May/Jun. 2011.

[18] Lu Bin, S.K. Sharma, "A Literature Review of IGBT Fault Diagnostic and Protection Methods for Power Inverters", IEEE Trans. Ind. Appl., sept./oct. 2009, Vol. 45, no. 5, pp. $1770-1777$.

[19] L. Dulau, S. Pontarollo, A. Boimond, J.-François Garnier, N. Giraudo, and O. Terrasse, "A New Gate Driver Integrated Circuit for IGBT Devices with Advanced Protections," IEEE Trans. Power Electron., vol. 21, no. 1, pp. 38-44, 2006.

[20] W. Sleszynski, J. Nieznanski, and A. Cichowski, "Open-transistor fault diagnostics in voltage-source inverters by analyzing the load currents", IEEE Trans. Ind. Electron., vol. 56, no. 11, pp. 4681-4688, Nov. 2009.

[21] J. O. Estima and A. J. Marques Cardoso, "A new approach for real-time multiple open-circuit fault diagnosis in voltage-source inverters", IEEE Trans. Ind. Appl., vol. 47, no. 6, pp. 2487-2494, Nov./Dec. 2011.

[22] A. Kolli, O. Bethoux, A. De Bernardinis, E. Laboure, G. Coquery, "Space-Vector PWM Control Synthesis for an H-Bridge Drive in Electric Vehicles," IEEE Trans. Veh. Technol., Vol. 62, no. 6, pp. 2441 2452, July 2013.

[23] S. Bolognani, M. Zordan, M. Zigliotto, "Experimental fault-tolerant control of a PMSM drive," IEEE Trans. Ind. Electron., Vol. 47, no. 5, pp. 1134 - 1141, Oct. 2000.

[24] F. Zidani, M.E.H. Benbouzid, D. Diallo, M.S. Nait-Said, "Induction motor stator faults diagnosis by a current Concordia pattern-based fuzzy decision system", IEEE Trans. Energy Convers., Dec. 2003, Vol. 18, no. 4, pp. $469-475$

[25] B. Mecrow, A. Jack, J. Haylock, and J. Coles, "Fault-tolerant permanent magnet machine drives", IEE - Elect. Power Appl., vol. 143, no. 6, pp. 437-442, Nov. 1996.

[26] C. H. Sneessens, T. Labbé, F. Baudart, F. Labrique, and E. Matagne, "Modelling and torque control of a five phase PMSM synchronous motor using tooth concentrated windings technology", in Proc. 8th Int. Symp. Adv. Electromech. Motion Syst., Electromotion, 2009, pp. 1-6.

[27] T. Labbé, B. Dehez, and F. Labrique, "Two phase operation for a three phase PMSM using a control model based on a Concordia like transform associated to a classic Park transform," Math. Comput. Simul., vol. 81, no. 2 , pp. $315-326$, Oct. 2010

[28] B. Vafakhah, J. Salmon, and A. M. Knight, "Interleaved Discontinuous Space-Vector PWM for a Multilevel PWM VSI Using a Three-Phase Split-Wound Coupled Inductor," IEEE Trans. Ind. Appl., vol. 46, no. 5, pp. 2015-2024, Sept.-Oct. 2010.

[29] Y. Xiong, S. Sun, H. Jia, P. Shea, and Z. J. Shen, "New Physical Insights on Power MOSFET Switching Losses," IEEE Trans. Power Electron., vol. 24, no. 2, pp. 525-531, Feb. 2009.

[30] G. Coquery, S. Carubelli, J.P. Ousten, R. Lallemand, F. Lecoq, D. Lhotellier, V. de Viry and Ph. Dupuy, "Power Module Lifetime Estimation from Chip Temperature Direct Measurement in an Automotive Traction Inverter," Microelectronics Reliability, vol. 41, no. 9, pp. 1695-1700, Sept.-Oct. 2001.

[31] Y. Xiong, S. Sun, H. Jia, P. Shea, and Z. J. Shen, "New Physical Insights on Power MOSFET Switching Losses," IEEE Trans. Power Electron., vol. 24, no. 2, pp. 525-531, 2009.

[32] M. van der Geest, H. Polinder, J. A. Ferreira, "Influence of PWM switching frequency on the losses in PM machines", International Conference on Electrical Machines (ICEM 2014), pp. 1243 - 1247, DOI: 10.1109/ICELMACH.2014.6960341

[33] F. Baudart, B. Dehez, E. Matagne, D. Telteu-Nedelcu, P. Alexandre, F. Labrique, "Torque Control Strategy of Polyphase Permanent-Magnet Synchronous Machines With Minimal Controller Reconfiguration Under Open-Circuit Fault of One Phase", IEEE Trans. Ind. Electron., vol. 59 , no. 6, pp $2632-2644,2012$.

[34] Yantao Song, Bingsen Wang, "Evaluation Methodology and Control Strategies for Improving Reliability of HEV Power Electronic System", IEEE Trans. Veh. Technol., Vol. 63, no. 8, pp. 3661 - 3676, Oct. 2014.

[35] N. Bianchi, S. Bolognani, and M.D. Pré, "Strategies for the fault-tolerant current control of a five-phase permanent-magnet motor," IEEE Trans. Ind. Appl., vol. 43, no. 4, pp. 960-970, Jul./Aug. 2007.

[36] S. Dwari and L. Parsa, "Fault-tolerant control of five-phase permanent magnet motors with trapezoidal back EMF," IEEE Trans. Ind. Electron., vol. 58, no. 2, pp. 476-485, Feb. 2011.

[37] D. S. Naidu, "Calculus of Variations and Optimal Control," in Optimal control systems, August 27, 2002 by CRC Press, USA: Florida. 
[38] V. Ngo, T. Hofman, M. Steinbuch, A. Serrarens, "Optimal Control of the Gearshift Command for Hybrid Electric Vehicles”, IEEE Trans. Veh. Technol., Vol. 61, no. 8, pp. 3531 - 3543, Oct. 2012.

[39] J. D. Ede, K. Atallah, J. Wang, and D. Howe, "Effect of optimal torque control on rotor loss of fault-tolerant permanent magnet brushless machines," IEEE Trans. Magn., vol. 38, no. 5, pp. 3291-3293, Sep. 2002 .

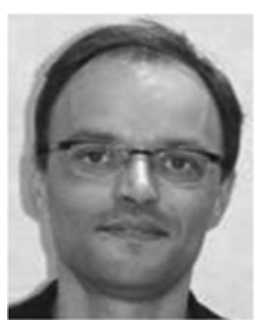

O. Béthoux (M 09) received the M.Sc. degree from the Ecole Centrale de Lille, Lille, France, in 1990, the teaching degree "Agregation" in 1997 and a Ph.D. from the University of Cergy-Pontoise, France, in 2005. From 1992 to 1997, he was a Research Engineer with the Alcatel Alsthom Research Center, France. Since 2006, he has been an Assistant Professor with the GeePs Laboratory and the IUT of Cachan.

His main research interests include analysis, design, and control of electric machines, fault diagnosis of electric drives, and advanced control techniques and energy management of fuel cells and photovoltaic cells.

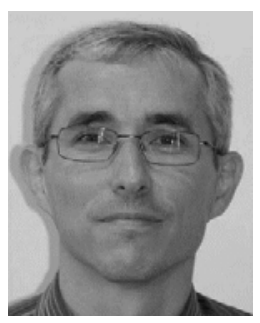

E. Labouré received the M.Sc degree in electrical engineering from the Institut National des Sciences Appliquées de Lyon (France) in 1989, the teaching degree "Agregation", the M.Sc. and Ph.D. degrees from the École Normale Supérieure de Cachan (France) in 1990, 1991 and 1995 respectively. Until 2008, he was an assistant professor at the Ecole Normale Supérieure de Cachan. From 2008, he has been a Professor at the University Paris-sud. He is currently working in the ECO2 group of Laboratory GeePs. His research interests include design and control of Power Electronics systems and Integration in Power Electronics.

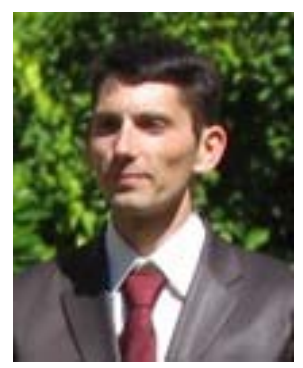

Ghislain Remy (M'06) Ghislain Remy (M'06) was born in Epinal, France, in 1977. He received the teaching degree "Agregation" from the Ecole Normale Supérieure de Cachan, France in 2001, and the Ph.D. degree from the Ecole Nationale Supérieure d'Arts et Métiers (ENSAM) of Lille, France in 2007. From 2008, he has been an associate professor at the Université Paris-Sud, France. His research interests originally included design and control of electromechanical systems with multi-domain and multi-level approaches. Since 2014, his research focus has changed to the design and optimization of robotic systems in order to improve the learning of emotions and social interaction for children with high-functioning autism.

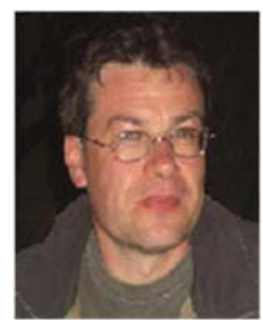

E. Berthelot received his electrical engineering degree from CNAM-Paris. Since 1991, he has been an R\&D engineer and has joined the Group of electrical engineering, Paris (GeePs) in xxx. In this research group, he has been responsible for various technological platforms including drive control systems test benches, a hydrogen PEM fuel cell setup, a magnetostrictive platform, and a non-destructive testing platform. 